\title{
HELPLESS BEHAVIOR
}

\author{
Christopher PETERSON \\ Department of Psychology, University of Michigan, 580 Union Drive, Ann Arbor, MI 48109-1346, U.S.A.
}

(Received 23 April 1992)

\begin{abstract}
Summary-In the present research, we investigated helpless behavior and the responses it elicits from others. Study One used the act-frequency approach to develop a self-report measure of prototypically helpless behaviors. In a sample of college students $(n=75)$, this measure was validated against ratings by others. Many of the prototypically helpless behaviors we identified were interpersonal in nature, implying that they entail dependency and perhaps manipulativeness. In Study Two, we asked young adult $(n=249) S$ s how they responded to people who showed varying amounts of helplessness. The most frequent response was trying to help the helpless individual feel better. As the frequency of helpless behavior increased, people were less likely to try to make him or her feel better, less likely to go along with the helpless individual, more likely to become angry and more likely to ignore or avoid this individual. Implications of these results for applications of the learned helplessness model were discussed, in particular the need to be cautious in assuming that all instances of observed passivity are good examples of learned helplessness.
\end{abstract}

\section{INTRODUCTION}

One of the most popular theories in contempory psychology is the learned helplessness model (Maier \& Seligman, 1976). It provides a succinct explanation for the inappropriate passivity that may follow in the wake of people's experience with uncontrollable events. According to the helplessness model, people experiencing uncontrollability first learn that outcomes elude their control and then generalize this belief about their own helplessness to new situations where it produces difficulties for them.

The helplessness model has been used to make sense of a variety of failures of human adaptation: depression, academic failure, victimization, athletic setbacks, poor work performance, illness and even early death (Peterson, 1990; Peterson \& Barrett, 1987; Peterson \& Seligman, 1983, 1984, 1987; Peterson, Maier \& Seligman, 1993; Seligman \& Schulman, 1986). However, questions can be raised about the reasonableness of some of these applications (Peterson \& Bossio, 1989; Peterson, Zaccaro \& Daly, 1986). Some may be too zealous, assuming that each and every instance of observed passivity is the result of the processes hypothesized by the learned helplessness model.

Helplessness theorists have been explicit that constructs such as one's expectations of responseoutcome independence are sufficient but not necessary for helplessness to develop (Peterson \& Seligman, 1984). There exist other routes to helplessness, including-for example-contingent reward of passivity and/or punishment of activity (e.g. Baltes \& Skinner, 1983). Because the helplessness model suggests preventive or ameliorative interventions (Seligman, 1981), there is considerable risk in misidentifying particular instances of passivity as learned helplessness.

These ideas provided the point of departure for the present studies, which concerned themselves with helpless behavior and how to conceive it. The learned helpless model defines helplessness in terms of the processes that give rise to it, i.e. uncontrollable events $\rightarrow$ expectations of responseoutcome independence $\rightarrow$ inappropriate passivity. In the present research, we started with actual examples of helplessness and asked how well they conformed to the definition of the learned helplessness model.

In Study One, we generated instances of helpless behavior by using the act-frequency approach described by Buss and Craik (1984). This stategy of assessing psychological states and dispositions regards constructs like helplessness as a way of categorizing and summarizing the "acts" (behaviors) of a person. To say that someone is helpless is to say that he or she displays a high frequency of helpless acts over a given period of time. To say that this individual is not helpless is to say that he or she displays a low frequency of helpless acts. 
What specific behaviors constitutes helpless acts? Buss and Craik (1984) believe that this question is best answered empirically. First, one solicits nominations of various behaviors reflecting the psychological state that one wants to study. Second, one asks people to rate how good an example of that psychological state each behavior is. The good examples are termed prototypical acts, and they tend not to reflect other psychological states.

We followed this strategy to identify examples of helplessness.* Then we asked $S$ s to report how frequently during the past month they had performed these prototypically helpless behaviors. To validate this measure, we followed Buss and Craik's (1984) procedure of devising a parellel questionnaire to be completed by a close friend of the $S$.

In Study Two, we asked $S$ s to report on how they responded to people who display varying degress of helpless behavior, using the prototypical acts we identified in Study One. If these behaviors reflect helplessness as conceived by the helplessness model, then they should meet with indifference from others, as opposed to such contingent reactions as assistance, reassurance or anger. This after all is what learned helplessness means: behaviors independent of outcomes.

\section{STUDY ONE}

\section{Method and results}

Overview. There were three phases in Study One. First, college students nominated behaviors that reflected helplessness, depression or anxiety. Second, another group of college students rated each of these nominated behaviors in terms of how well it exemplified each of these psychological states. Third, the best examples of helpless behaviors were included in a self-report questionnaire completed by yet another group of college students, along with a parallel measure completed by a friend.

Subjects. All of the $S$ s were introductory psychology students at Virginia Tech, participating in the research for extra credit toward their final grade. In the three phases, $63 S \mathrm{~s}$ (35 females, 28 males), $27 S \mathrm{~s}$ (13 females, 14 males) and $75 S \mathrm{~s}$ (41 females, 34 males) participated, respectively.

Act nomination. As part of a larger study of the behaviors exemplifying different states of psychopathology, behaviors reflecting helplessness, depression and anxiety were solicited by asking the first group of $S s(n=63)$ to respond to the following introductions:

Think of the three most helpless individuals you know, people who are passive, ineffective and unresponsive. Write their first initial only on these lines:

person 1:- person 2:- person 3:-

With these individuals in mind, write down five specific acts or behaviors that they have performed that reflect or exemplify their helplessness. Do not write down synonyms or adjectives pertaining to helplessness. Instead, describe specific things that these people $d o$. For instance, a helpless person might stay in pajamas all day long.

The questionnaire about depression was identical, except that it asked about the behavior of indjviduals who were "depressed ... sad, blue and unhappy." The anxiety questionnaire asked about the behavior of those who were "anxious ... nervous, jittery and worried." Each $S$ responded to just one of these questionnaires, which means that in each case, $21 S \mathrm{~s}$ nominated acts.

Act prototypicality. The nominated acts were combined into a single list by eliminating redundancies and randomly ordering the remaining behaviors. A list of 199 acts resulted. The second group of subjects $(n=27)$ rated the prototypicality of these acts in accordance with the following instructions:

In this study, you are asked to make judgements about whether particular behaviors are good or bad examples of different psychological states: being anxious, being depressed and

\footnotetext{
*On a number of grounds, Block (1989) has recently criticized the act-frequency approach as a strategy of personality assessment. The thrust of his criticisms seems to be that the method is not as novel as Buss and Craik (1984) suggest. Regardless, the act-frequency approach remains highly suitable for the purpose of the present research: identifying the range of everyday behaviors that exemplify helplessness.
} 
Table 1. Prototypically helpless behaviours (Study One)

\begin{tabular}{lc}
\hline Behavior & Mean rating (7-point scale) \\
\hline Didn't leave house/apartment all day & 4.70 \\
Didn't cook for self & 4.78 \\
Was unable to fix a broken object & 4.78 \\
Cried & 4.81 \\
Gave up in the middle of doing something & 4.93 \\
Said negative things about self & 4.93 \\
Didn't study because "it doesn't matter" & 5.00 \\
Let someone take advantage of self & 5.00 \\
Asked others to do something for self & 5.11 \\
Didn't stand up for self & 5.15 \\
Didn't change a strategy that does not work & 5.26 \\
Failed to make an important decision & 5.37 \\
Stayed in an abusive relationship & 5.44 \\
Let someone else make a decision & 5.56 \\
Used another person as a crutch & 5.63 \\
Refused to do something on own & 5.78 \\
\hline
\end{tabular}

being helpless. Below are listed several hundred behaviors-things that a person might do. For each behavior, you are to rate how good an example it is of each psychological state. Use a 7-point scale, where "7" means that you feel the behavior is a very good example of your idea of being anxious (or depressed or helpless), where " 4 " means the behavior fits your idea moderately well, and where " 1 " means the behavior is a very poor example. Use other numbers on the 7-point scale to indicate intermediate judgments.

For each behavior, you will make three different ratings. Do not let these ratings influence each other. Behaviors may be good examples of all three psychological states, two of them, one of them, or none at all.

Rating reliabilities were ascertained by computing alpha coefficients. In each case, reliability was respectably high: 0.94 for anxiety, 0.04 for depression and 0.89 for helplessness. Ratings by men and by women correlated highly with each other over the 199 behaviors: 0.90 for anxiety, 0.89 for depression and 0.82 for helplessness.

"Helpless" behaviors and "depressed" behaviors overlapped with each other and were distinct from "anxious" behaviors. In other words, ratings of helplessness correlated positively over the 199 behaviours with ratings of depression $(r=0.57)$, whereas these ratings correlated negatively with ratings of anxiety $(r=-0.65$ and $r=-0.51$, respectively). Seventeen of the behaviors most representative of helplessness* were chosen for the Helpless Behavior Questionnaire (see Table 1).

Validation. The $75 \mathrm{Ss}$ in the third phase of the investigation completed several questionnaires. $\dagger$ The Helpless Behavior Questionnaire was composed of the 17 behaviors in Table 1 combined with 7 filler behaviors taken from Buss and Craik (1984) that exemplified extraversion. For each behavior, $S \mathrm{~s}$ wrote how many times they performed it during the past month.

Subjects were also given a questionnaire that paralleled the Helpless Behavior Questionnaire and was to be completed by a friend. According to the instructions, the friend was to report on the $S$ 's behavior during the past month. These questionnaires were completed independently of the $S$ and mailed directly back to the researchers, using a stamped envelope that was provided. Of the $75 \mathrm{Ss}$, the friends of $74(99 \%)$ returned the questionnaire.

Responses by the friends were used to validate the responses of the subjects. Table 2 compares the mean number of helpless behaviors reported by $S \mathrm{~s}$ and their friends, along with the associated Pearson and intraclass correlations. Intraclass correlations reflect not only similar rank-ordering of scores across $S$ s but also agreement regarding magnitude. As can be seen, the majority of Pearson correlations were significant, and the majority of the intraclass correlations were substantial.

-The behaviors most representative of anxiety, with their mean ratings in parentheses, were: can't sit still (6.33); talks quickly (6.22); paces (6.11); drums tables with fingers (6.04); chews pencil (5.96); bites nails (5.78); bounces leg while sitting (5.78); is impatient while waiting (5.70); darts eyes around constantly (5.59); and sweats while taking exams (5.59).

The behaviors most representative of depression, with their mean ratings in parentheses, were: talks about suicide (6.52); says negative things about self (6.44); feels sorry for self (6.30); cries (6.22); never laughs (6.15); speaks of death or dying (6.15); never smiles (6.04); and drinks too much alcohol (6.04).

$\dagger S s$ also completed several other questionnaires not relevant to the present purposes. 
Table 2. Helpless behaviors: means and correlations (Study One)

\begin{tabular}{lcccc}
\hline Behavior (see Table 1) & $\begin{array}{c}S \text { responses } \\
\text { mean (SD) }\end{array}$ & $\begin{array}{c}\text { Friend responses } \\
\text { mean (SD) }\end{array}$ & $r$ & $\begin{array}{c}\text { Intraclass } \\
\text { correlation }\end{array}$ \\
\hline Didn't leave house & $1.0(2.3)$ & $0.9(1.8)$ & $0.24^{*}$ & 0.70 \\
Didn't cook & $9.3(15.7)$ & $9.7(20.9)$ & $0.62^{* *}$ & 0.72 \\
Unable to fix object & $0.7(1.2)$ & $0.9(1.5)$ & 0.03 & 0.58 \\
Cried & $2.2(4.1)$ & $1.2(1.8)$ & $0.57^{* *}$ & 0.66 \\
Gave up & $3.0(3.8)$ & $2.2(3.6)$ & $0.26^{*}$ & 0.48 \\
Said negative things & $7.3(12.3)$ & $7.7(14.2)$ & $0.30^{*}$ & 0.88 \\
Didn't compete & $2.0(2.8)$ & $1.3(3.4)$ & -0.02 & 0.78 \\
Didn't study & $4.1(5.8)$ & $2.5(4.7)$ & $0.31^{*}$ & 0.63 \\
Someone takes advantage & $2.3(6.3)$ & $2.3(7.1)$ & $0.89^{* *}$ & 0.69 \\
Others do things & $5.1(4.1)$ & $5.0(9.1)$ & $0.23^{*}$ & 0.69 \\
Didn't stand up & $1.6(2.8)$ & $0.9(2.3)$ & $0.25^{*}$ & 0.74 \\
Didn't change strategy & $0.9(1.8)$ & $0.9(2.5)$ & 0.08 & 0.65 \\
Failed to make decision & $1.3(2.2)$ & $1.0(2.4)$ & 0.19 & 0.47 \\
Abusive relationship & $0.8(3.3)$ & $0.8(3.7)$ & $0.93^{* *}$ & 0.71 \\
Someone makes decisions & $2.8(3.0)$ & $4.2(11.2)$ & $0.31^{*}$ & 0.59 \\
Another person as crutch & $1.6(3.1)$ & $1.4(2.0)$ & 0.11 & 0.97 \\
Refused something on own & $1.5(2.8)$ & $1.1(2.2)$ & $0.28^{*}$ & 0.97 \\
\hline
\end{tabular}

$* P<0.05$. "P $P 0.001$.

A composite measure of helpless behavior was formed by summing the $S$ 's scores for the 17 behaviors on the Helpless Behavior Questionnaire (mean $=47.65, \mathrm{SD}=41.23$ ). The reliability of this measure, estimated by coefficient alpha, was 0.69 .

\section{Discussion}

Particular behaviors that exemplify helplessness can be identified. Subjects in Study One agreed on good vs bad examples of helpless acts. It is interesting that the best examples of helplessness were not rated quite as highly as the best examples of anxiety and depression (compare Table 1 with the footnote on p. 291). Perhaps helplessness is less a "natural category" of behavior than anxiety and depression (Cantor, Smith, French \& Mezzich, 1980). If this is so, then the variety of behaviors to which helplessness theory seems to apply can be understood, as well as its less-than-perfect fit in almost every case (Peterson \& Bossio, 1989).

Both $S \mathrm{~s}$ and their friends agreed about the frequency that the $S \mathrm{~s}$ performed prototypically helpless behaviors, thus validating the self-report measure of helplessness we devised. Further, helpless behaviors cohered, although only to a moderate degree. That "helplessness" is a psychological state of somewhat limited generality is an important finding granted the central role that contemporary theories assign to helplessness and its cognates (Peterson \& Stunkard, 1989).

Inspection of the particular behaviors identified by $S$ s as prototypically helpless (see Table 1) shows that many fail simply on the face of it to fit the definition of the model. Instead, the prototypical instances of helplessness tended to be social in nature: never does things on own; lets others make decisions; uses other people as crutches; and asks others to do things. The helpless individual involves another person in his or her plight, and helplessness as identified here seems to overlap considerably with interpersonal dependency.

The question is thereby raised whether such instances of helplessness are as ineffectual as one might think by terming them helpless. Perhaps these behaviors represent a ploy or tactic, used by individuals to manipulate others into doing what they wish. In their review of theories of depression, Arieti and Bemporad (1978) explicitly dismissed the analogy between learned helplessness and depression, calling it misleading. Depressed people proclaim their helplessness, according to Arieti and Bemporad (1978), but their behavior may be highly instrumental.

The results of Study One do not allow us to conclude that prototypically helpless behaviors are futile or not. We therefore undertook a second investigation, to see what kinds of reactions the helpless behaviors identified in Study One elicit from other people.

\section{STUDY TWO}

\section{Method}

Subjects and procedure. Research participants in this investigation were 249 young adults (133 females, 116 males) recruited in public places on the University of Michigan campus by researchers who asked them to volunteer to complete a brief questionnaire. 
Table 3. Reactions to helpless behavior (Study Two)

\begin{tabular}{lcc}
\hline Reaction (see text) & Mean (SD) & $\begin{array}{c}\text { Correlation with amount } \\
\text { of displayed helplessness }\end{array}$ \\
\hline Went along with friend & $3.65(1.62)$ & $-0.18^{*}$ \\
Tried to make friend feel better & $5.30(1.52)$ & $-0.23^{* *}$ \\
Got angry at friend & $3.20(1.78)$ & $0.28^{* *}$ \\
Ignored/avoided friend & $2.41(1.68)$ & $0.54^{* *}$ \\
\hline
\end{tabular}

$* P<0.01$ **P<0.001.

Questionnaire. The questionnaire completed by $S \mathrm{~s}$ had the following instructions:

Think of one person you know well, and answer the following questions about this person. Think of anyone you wish as long as they have been generally unhappy (happy) during the past month or so.

Half of the $S$ s were given a questionnaire asking about a generally unhappy friend, and the other half of the $S \mathrm{~s}$ were asked about a generally happy friend. The intent of these instructions was to introduce variation into the sort of friend described with respect to helplessness. We used the terms "unhappy" and "happy" rather than "helpless" and "not helpless" to avoid a blatant demand characteristic. The instructions then went on to say:

Listed below are a number of behaviors. In the line in front of each behavior, write a number that corresponds to how many times your friend performed this behavior during the past month.

Following were the 17 prototypically helpless behaviors shown in Table 1.

Finally, $S$ s were asked to answer the following questions using 7-point scales, from $1=$ not at all to $7=$ always:

When this person does the sorts of things listed above [i.e. the helpless behaviors], how have you usually reacted during the past month?

(a) I went along with what he/she wanted.

(b) I tried to make him/her feel better.

(c) I got angry at him/her.

(d) I ignored or avoided him/her.

\section{Results}

A composite helplessness score was computed by summing the 17 items.* These scores indeed distinguished between the generally happy and generally unhappy individuals who were described ( 25.53 vs 47.54 , respectively, $t=6.49, P<0.001$ ).

Table 3 shows the means and standard deviations of the four reactions about which we asked. The three most common reactions were those contingent on what the individual did: going along with the person; trying to make the person feel better; and getting angry at the person. The least likely reaction was the one predicted by the learned helplessness model: avoiding or ignoring the person. So, the conclusion again follows that prototypically helpless behavior may not be well described by the learned helplessness model, because these behaviors elicit particular reactions from others, sometimes good and sometimes bad.

This conclusion is clarified by the correlations we computed between the likelihood of these reactions and the degree to which the person acted helplessly (again see Table 3). As the extent of helpless behavior increased, the willingness of the $S \mathrm{~s}$ to go along with them or to try and make them feel better decreased. Instead, they became more likely to get angry, and more likely to ignore or avoid the helpless individual.

\footnotetext{
* For reasons of coding convenience in Study Two, responses to the helplessness items that were 10 or greater were recorded on our coding sheets as 9, which means that the composite scores in Study Three were somewhat lower and less variable than those in Study One. The difference is methodological, not substantive.
} 


\section{Discussion}

In Study One, we found that many prototypically helpless behaviors were interpersonal. People who act helplessly seemed to be dependent upon others. These findings raised the question about how best to interpret such helpless behaviors. Are they ineffectual and futile, like the behaviors of concern to the learned helplessness model (Seligman, 1975)? Or are they instrumental, a style of presentation that manipulates other people into doing what the ostensibly helpless person wants?

The results of Study Two show that both answers are correct, depending on the amount of helpless behavior the individual typically shows. Helpless behavior as studied here appears to be instrumental in small amounts, reacted to with cooperation and attempts to make the helpless individual feel better. However, helpless behavior in large amounts proves futile in winning support and assistance from others. Instead, the person who displays a large number of prototypically helpless behaviors is eventually reacted to with anger or avoidance.

Nonetheless, these findings imply that the route to helplessness as operationalized here is not necessarily the one hypothesized by the learned helpless model. According to the model, helplessness results from experience with uncontrollable events: those which occur independently of one's actions. But the present results suggest that helpless behavior may begin as an instrumental tactic, only to backfire on an individual who too frequently acts helplessly in the presence of others.

Our conclusions are offered with some tentativeness, because questions can be raised about the procedure of Study Two. We relied on people's reports on how they reacted to someone who displayed certain behaviors, and these reports could be colored by social desirability considerations. Or more simply, some $S$ s might be unable to say how they usually react (Nisbett \& Wilson, 1977). A better procedure would certainly have been to observe actual interactions between $S$ s and helpless or nonhelpless individuals, in the way that Coyne (1976) has studied the response of $S \mathrm{~s}$ to depressed individuals.

\section{GENERAL DISCUSSION}

We have discussed two studies concerned with helpless behavior. As measured by the act-frequency approach, "helplessness" appears to be an individual difference of some-but not great-generality. Because psychological theory often speaks of helplessness as a monolithic state, this finding points to the need for greater attention to the parameters of ineffectual responding.

Many of the helpless acts we identified reflect interpersonal dependence, meaning that the helpless individual turns to others when unable or unwilling to accomplish a goal. In small doses, this strategy may be instrumental, because others will try to make the helplessly behaving individual feel better, and they will go along with what this person wishes. In large doses, helplessness indeed proves ineffectual, because it leads others to become angry and to turn away. The interpersonal context of helplessness deserves more attention than it has previously received, particularly in terms of how someone becomes helpless in the first place.

The most general implication of our results is that the learned helplessness model should be applied to particular instances of passivity with some caution. In several ways, prototypical examples of helplessness are poorly captured by the model. Those who behave helplessly cannot be automatically assumed to live in an unresponsive world.

Abramson, Metalsky and Alloy (1989) examined the learned helplessness model as it applies to depression and concluded that some but not all cases of depression are the result of the processes specified by the model. They suggested that researchers in the future attempt to classify instances of depression in terms of their etiology; one category would be a learned helplessness depression, but there additionally would be other categories. We close with a similar suggestion about helplessness per se. A classification of helplessness based on causes is a worthy goal for future research.

Acknowledgements-Michelle Dean, Stacey Janoff, Beth Klavens and Laura Vorst helped gather data. We thank Lisa M. Bossio for her helpful editorial advice. 


\section{REFERENCES}

Abramson, L. Y., Metalsky, G. I. \& Alloy, L. B. (1989). Hopelessness depression: a theory-based subtype of depression. Psychological Review, 96, 358-372.

Arieti, S. \& Bemporad, J. (1978). Severe and mild depression. New York: Basic Books.

Baltes, M. M. \& Skinner, E. A. (1983). Cognitive performance deficits and hospitalization: learned helplessness, instrumental passivity, or what? Journal of Personality and Social Psychology, 45, 1013-1016.

Block, J. (1989). Critique of the act frequency approach to personality. Journal of Personality and Social Psychology, 56, 234-245.

Buss, D. M. \& Craik, K. H. (1984). Acts, dispositions, and personality. In Maher, B. A. (Ed.), Progress in experimental personality research, (Vol. 13, pp. 241-301). New York: Academic Press.

Cantor, N., Smith, E., French, R. deS. \& Mezzich, J. (1980). Psychiatric diagnosis as prototype categorization. Journal of Abnormal Psychology, 89, 181-193.

Coyne, J. C. (1976). Depression and the response of others. Journal of Abnormal Psychology, 85, 186-193.

Maier, S. F. \& Seligman, M. E. P. (1976). Learned helplessness: theory and evidence. Journal of Experimental Psychology: General, 105, 3-46.

Nisbett, R. E. \& Wilson, T. W. (1977). Telling more than we can know: verbal reports on mental processes. Psychological Review, 84, 231-259.

Peterson, C. (1990). Explanatory style in the classroom and on the playing field. In Graham, S. \& Folkes, V. S. (Eds.), Attribution theory: Applications to achievement, mental health, and interpersonal confict (pp. 53-75). Hillsdale, NJ: Erlbaum.

Peterson, C. \& Barrett, L. C. (1987) Explanatory style and academic performance among university freshmen. Journal of Personulity and Social Psychology, 53, 603-607.

Peterson, C. \& Bossio, L. M. (1989). Learned helplessness. In Curtis, R. C. (Ed.), Self-defeating behaviors, (pp. 235-257). New York: Plenum.

Peterson, C., Maier, S. F. \& Seligman, M. E. P. (1993). Learned helplessness: A theory for the age of personal control. New York: Oxford.

Peterson, C. \& Seligman, M. E. P. (1983). Learned helplessness and victimization. Journal of Social Issues, 39, $103-116$.

Peterson, C. \& Seligman, M. E. P. (1984). Causal explanations as a risk factor for depression: theory and evidence. Psychological Review, 91, 347-374.

Peterson, C. \& Seligman, M. E. P. (1987). Explanatory style and illness. Journal of Personality, 55, 237-265.

Peterson, C. \& Stunkard, A. J. (1989). Personal control and health promotion. Social Science and Medicine, $28,819-828$.

Peterson, C. \& Villanova, P. (1988). An Expanded Atributional Style Questionnaire. Journal of Abnormal Psychology, 97, 87-89.

Peterson. C., Zaccaro, S. J. \& Daly, D. C. (1986). Learned helplessness and the generality of social loafing. Cognitive Therapy and Research, 10, 563-569.

Seligman, M. E. P. (1975). Helplessness: On depression, development, and death. San Francisco: Freeman.

Seligman, M. E. P. (1981). A learned helplessness point of view. In Rehm, L. P. (Ed.), Behavior therapy for depression: Present status and future directions, (pp. 123-141). New York: Academic Press.

Seligman, M. E. P. \& Schulman, P. (1986). Explanatory style as a predictor of productivity and quitting among life insurance agents. Journal of Personality and Social Psychology, 50, 832-838. 